\title{
COFLEX: FLEXIBLE BRACELET ANTI COVID-19 TO PROTECT CONSTRUCTION WORKERS
}

\author{
E. Laurini ${ }^{1}$, M. Rotilio ${ }^{1}$, P. De Berardinis ${ }^{1}$, P. Vittorini ${ }^{2}$, F. Cucchiella ${ }^{3}$, G. Di Stefano ${ }^{4}$, G. Ferri ${ }^{3}$, V. Stornelli ${ }^{3}$, L. Tobia ${ }^{2}$ \\ ${ }^{1}$ Dept. of Civil, Construction-Architectural and Environmental Engineering, University of L'Aquila, L'Aquila, Italy - \\ elelaurini@yahoo.it, (marianna.rotilio,pierluigi.deberardinis@univaq.it) \\ ${ }^{2}$ Dept. of Life, Health and Environmental Sciences, University of L'Aquila, L'Aquila, Italy - \\ (pierpaolo.vittorini, loreta.tobia)@univaq.it \\ ${ }^{3}$ Dept. of Industrial and Information Engineering and Economics, University of L'Aquila, L'Aquila, Italy - \\ (federica.cucchiella, giuseppe.ferri, vincenzo.stornelli@univaq.it) \\ ${ }^{4}$ Dept. of Information Engineering, Computer Science and Mathematics, University of L'Aquila, Italy - gabriele.distefano@ univaq.it
}

KEY WORDS: Wearable technology, Smart DPI, Covid-19, Safety, Construction site

\begin{abstract}
:
To implement the protocol contrasting the diffusion of Covid-19, the employer is required, to ensure the safety and health of the worker at work, to adopt measures related to the control of body temperature (with respect for privacy), the minimum distance during work and all other activities such as breaks, canteen breaks, access to toilets, in addition to the adoption of specifically developed safety procedures, such as e.g. the use of man-down detection devices. In this context, the project aims to illustrate a system able of providing support in the safeguarding of workers' health on construction sites. This system, based on information received from sensors capable of identifying workers' positions (e.g., if less than $1 \mathrm{~m}$ away) and their vital parameters (e.g., body temperature, gasped breathing), as well as moving objects inside the construction site area (e.g., to check if a worker is passing under a moving crane), will raise early alerts directly to the workers and/or to the central software, with respect for privacy, to immediately activate all the necessary measures to mitigate the risk. The system, based on the data communicated by the various sensors, will store and process them for the purpose of extracting useful information for risk management. The proposed system configured itself as a new product taking advantage from a high Technology Readiness Level maturated from the Smart Safety Belt already developed by some of the authors.
\end{abstract}

\section{INTRODUCTION}

Following the worldwide health emergency due to the spread of the COVID-19 virus, it is fundamental to use technological systems in order to use smart means in reducing the infection. The pandemic that is ongoing has in fact had, in addition to the tragic consequences in terms of victims, a very negative impact on the economy of all Countries. Bearing in mind the preeminent value of human life, a safe resumption of construction activity was necessary, limiting the economic burden in the implementation of safety protocols, as well as the burden of contagion. In Italy, Inail, the Italian National Institute for Insurance Against Occupational Accidents, had equated the Covid-19 infection in the insurance category of work-related injury. Moreover, the resumption of construction activity postpandemic was conditioned by the application of the provisions of the shared protocol, the latest on 24 March 2020, according to which the employer of the construction company will have to take responsibility for adopting measures regarding information, how to enter the company, hygienic precautions, directions for suppliers and subcontractors, cleaning and sanitising environments, safe distance and personal protective equipment, management of entries and exits of employees and the management of a symptomatic operator. In particular, it is necessary to verify work that may involve an interpersonal distance of less than one meter and temperature control (including through polling mechanisms and not only at the entrance to the site). This becomes even more important in the phase of rising infection, which will see restrictions imposed again in all areas of work. For this reason, a lightweight device was designed to be easily worn and falling into the category of "wearable technology", a solution with interactive products capable of communicating with portable devices such as smartphones and tablets and wearable items such as smartwatches, allowing great advantages in terms of safety, potentially being configured as life-saving tools for the operator in case of emergency or ensuring his protection in the case of a pandemic (Fig. 1). Born for the most difficult work environments, such as the steel industry or confined places, wearable technology is an expanding market that is capturing the interest of many researchers and designers, even within the construction site (Fig. 2). In this specific research field, among the most recent studies Nwaogu and Chan [1] employ wearable technologies to monitor workers in order to understand the impacts of work-related stress, as well as Liu et al. [2] and Jebelli et al. [3]. Kim et al. [4] study a modified version of an off - the - shelf wearable device while Sakhakarmi and Park [5] propose a wearable, tactile-sensing system as a means of communication. Finally Antwi-Afari et al. [6] focus attention on insole, in order to analyze the performance of workers for reasons related to safety on site while Kim and Ho [7] on relationship between wearable technologies and privacy. This latest study also analyzes the social aspects related to these issues, highlighting how facilitating social interaction among users and keeping personal information securely are keys to success in the dissemination of these devices.

In this international context, the research project "CoFlex" (a flexible bracelet anti covid-19 to protect construction workers)

\footnotetext{
* Corresponding author
} 
represents the implementation of a wearable technology already defined by some of the authors $[8]^{1}$, who had set the requirements that the system should have met based on their high experience in the field and following recent literature studies $[9,10]$. CoFlex is under development and is part of the so-called "4.0 solutions" for the protection of workers' health and safety at work. It was born in the research field of building production and the organization of the construction site by introducing principles of system innovation and process digitization. In fact, a concrete response to the growing demand for management and organized verification of the construction process on site and safety in the workplace can be given by the use of innovative digital technologies $[11,12]$. These represent the future of construction in terms of quality of construction, sharing of information, but above all in terms of Risk Management.

The bibliographic research carried out for the development of CoFlex also covered other very important topics in addition to that of wearable technologies. Among these, for example, studies concerning contact tracing [13], app for identifying the drivers of COVID-19 epidemics [14] were analyzed, as well as researches that highlight how the pandemic has impacted construction sites [15] and changed the concept of worker safety [16]. In this latter context, some authors [17] have analyzed the social implications of the pandemic on workers, highlighting the initial refusal to use technological systems followed by acceptance in the light of the benefits achieved.

The following paragraphs provide an overview of the Italian post-Covid-19 protocols adopted for the resumption of construction site activities, subsequently the CoFlex project is illustrated. The article closes by describing the main conclusions and application potential.
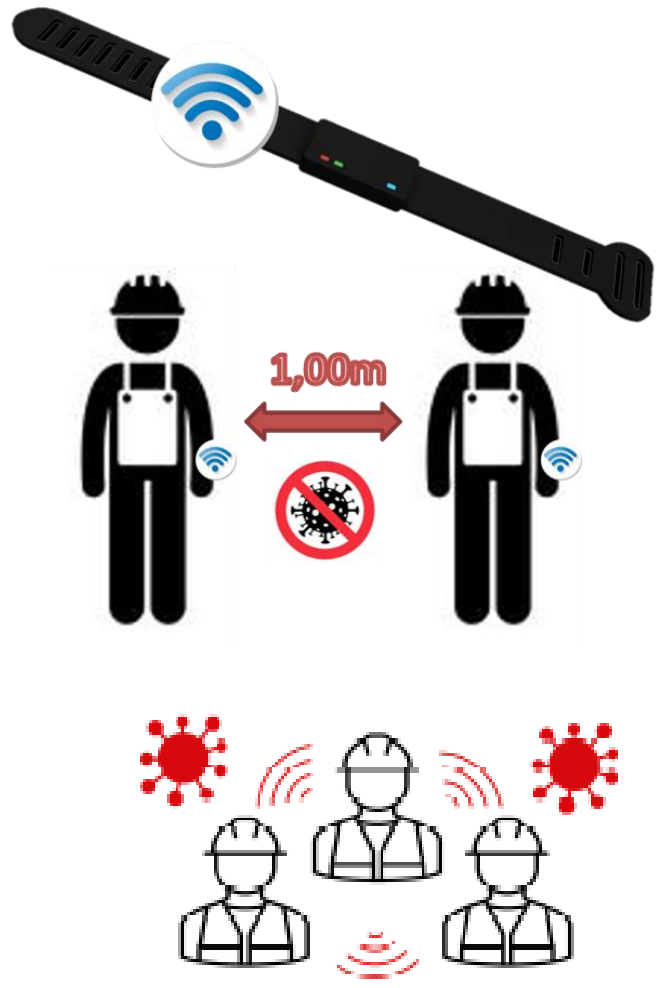

Figure 1: Schematic operation of the anti-Covid 19 device.

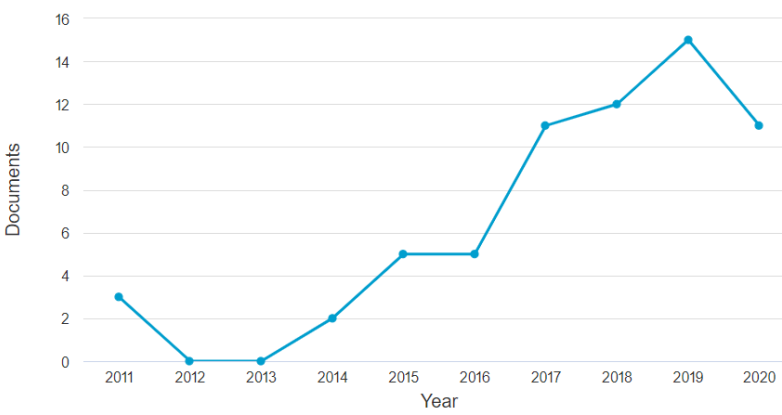

Figure 2: Growth trend in research interest in wearable technologies within the construction site (Source: Scopus database; Search range: 2010-2020; Search terms:

"wearable AND technology" AND "construction AND site")

\section{ITALIAN POST COVID PROTOCOLS FOR CONSTRUCTION SITES}

In Italy on 24/04/2020 the protocol for the contrast and containment of Covid-19 in construction sites was signed by the following actors [18]: The Ministry of Infrastructure and Transport, together with the Ministry of Labor and Social Policies and to trade union and labor representatives. This protocol was subsequently updated and modified. The fundamental rules that employers must adopt, and must have them adopted on construction sites, are very restrictive and concern the various aspects inherent in both the work and the management of common spaces. Among the most significant aspects, body temperature control is the most stringent obligation. In fact, if this temperature were higher than $37.5^{\circ} \mathrm{C}$, access to the site would not be allowed. Other provisions include the obligation to maintain a safe distance, use the personal protective equipment made available during work that does not allow to respect the interpersonal distance of one meter and maintain correct hygiene behavior. It is necessary to promptly inform the employer of the presence of any flu symptoms and access must be precluded to those who, in the last 14 days, have had contact with subjects who tested positive for Covid-19 or come from areas at risk according to the indications of the WHO.

If the work on site requires operating at an interpersonal distance of less than one meter and other organizational solutions are not possible, the use of masks and other protective devices (gloves, goggles, overalls, headphones) is still necessary.

The protocols also define the methods of access for suppliers / transporters external to the construction site: in particular, methods, routes and timing must be identified, in order to reduce the opportunities for contact with the workers. The drivers of the means of transport must remain on board their own vehicles: access to the closed common areas of the site is not allowed for any reason. In case of need they can use dedicated toilets. During loading and unloading activities, the transporter must comply with the strict minimum distance of one meter. If there is a transport service, the safety of workers must be guaranteed and respected during each movement, if necessary by using a greater number of vehicles and/or by providing for entries and exits from the site more flexible and staggered hours.

Other indications of the protocols concern cleaning and hygiene on the construction site: the employer must ensure daily cleaning and periodic sanitation of the changing rooms and common areas by limiting 
simultaneous access to such places. For the purposes of sanitation, the work vehicles with the related driving or piloting cabs must also be included. The same applies to service cars and rental cars and to work vehicles such as cranes and vehicles operating on site. The employer is required to verify the correct cleaning of the individual work tools, also providing specific detergent and making it available on site for the entire duration of the work performance. In the event of the presence of a Covid-19 virus positive person inside the construction site, it is necessary to clean and sanitize the premises, housing and vehicles in accordance with the provisions of circular no. 5443 of 22.02.2020 of the Italian Ministry of Health.

As regards the management of common spaces, it is limited, with the provision of continuous ventilation, a reduced time spent inside these spaces and with the maintenance of a safety distance of one meter between the people who occupy them. The employer must provide for the sanitation at least daily and the organization of places for the eating and changing rooms to leave the workers places for the storage of work clothes and guarantee them suitable sanitary conditions.

To organize the construction site during the period of the emergency due to Covid-19, companies will be able to reorganize the construction site and the work schedule also through the shifting of workers with the aim of reducing contacts, creating autonomous, distinct and recognizable groups and to allow a different articulation of the opening hours of the site both as regards opening, parking and exit (Fig.3).
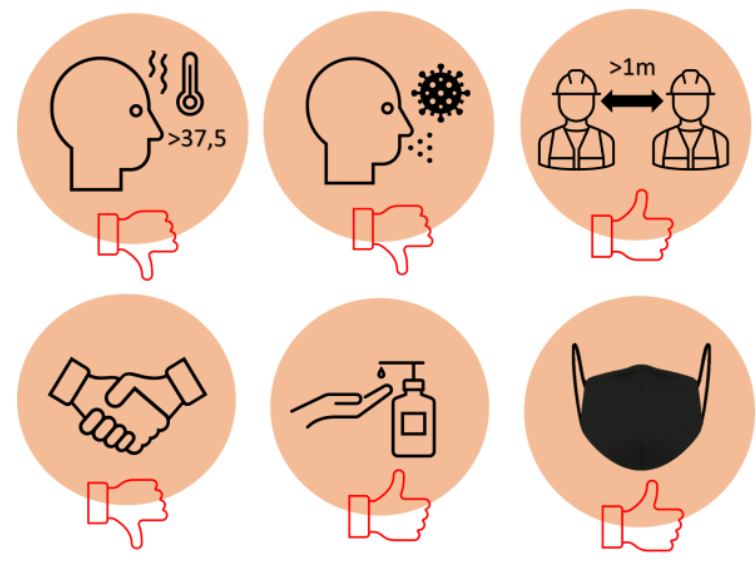

Figure 3: Anti Covid-19 security measures on construction sites

To comply with the rules and protocols defined due to the pandemic, the exploitation of new 4.0 technologies [19] can facilitate procedures and controls that in the long term could cause slowdowns in the execution of the works and, therefore, economic losses for business. Furthermore, if not respected effectively, they could lead to further infections.

\section{THE "COFLEX" RESEARCH PROJECT}

\subsection{Main functions}

The product will allow for each worker to monitor the interpersonal distance, body temperature, heart rate, oxygenation (in compliance with privacy regulations that provide the possibility of control, but not the recording of data), and in perspective the detection of PPE worn (e.g. gloves and masks), the position on the construction site (e.g. to report passage under a crane in motion) and falling (fainting, accidental fall, etc.). The system will issue early alerts to the worker and - always in respect of privacy - send the data to centralized software to take any necessary action to manage and mitigate the risk. Last but not least, the system will have a direct call SOS button if the operator feels he promptly needs help. The measurement of body temperature would be constant throughout the working day as well as the vital parameters, and the possibility of an unconscious man on the ground and a possible cause of contagion. The possibility of prevention through alerts would make it possible to avoid dangerous situations and the subsequent economic and health consequences for the worker, as well as the spread of contagion among workers who were in contact in certain places and at certain times.

Access to the data collected will be available remotely for security operators. In particular, the monitoring of the data collected by CoFlex will make it possible to control and mitigate the risk from Covid-19 and that related to the interaction between workers and among them and the workplace.

The remote transmission of data will make it possible to identify the physical state of the workers without contact and therefore without exposing other workers to risk. Furthermore, the continuous control of the workers' parameters allows to understand the work dynamics that led to the contagion, also to prevent others.

The products currently on the market do not have all the features of CoFlex. There are products that allow to check distances (eg, Smart Proximity, ZoneSafe PEDD) or to measure the body temperature in access to the construction site (eg, medical infrared thermometers for measuring body temperature without contact, both portable, you fix). But the study of the state of the art revealed that there are no products that systematize this data in order to provide integrated information, useful for the prevention and mitigation of risks. Therefore the market today is not yet able to satisfy the needs that CoFlex can satisfy instead.

Going into detail, the algorithms are innovative while all the HW is based on commercial purchasing elements already developed in the literature. A low-level FW will be developed capable of processing information from sensors (pulse oximeter, pulse counter, thermometers) and managing data transmission. A local middleware will then be developed capable of managing local alarms and routing data to a remote server. Finally, a web application will be developed for the management and visualization of data and the management of remote alarms.

Therefore, in its final version, CoFlex will reach a Technology Readiness Level (TRL) of eight and will classify itself as an industry leader by responding fully and effectively to the Covid19 emergency. In fact, a prototype of the final product will be created and put into operation in a real operating environment.

\subsection{Methodology}

The CoFlex project is based on a multidisciplinary approach in which knowledge of construction site needs is combined with electronic, informatic and medical ones. Given its complexity, research progress steps have been organized (Fig. 4). They are summarized below:

1. Study and design of project specifications.

2. Software development. This step aims to develop software capable of receiving data from sensors, storing them in full respect of privacy and 
extracting information useful for safeguarding health in relation to Covid-19.

3.

Definition of the electronic monitoring system and development of the hardware system. The latter involves a bench test phase with subsequent experimentation with reduced functionality.

4. The last phase aims to integrate all the previously defined components and to test the system in its entirety in order to obtain the final certification.

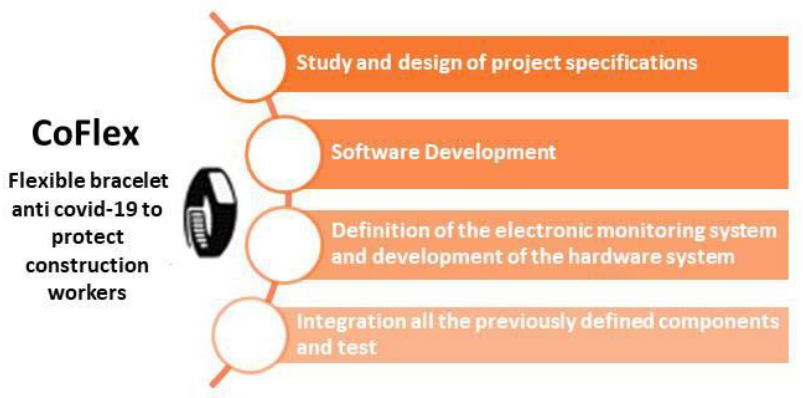

Figure 4: Methodological approach

\subsection{Results and impacts}

The results that CoFlex will allow to achieve, can be divided into "short term" and "long term" results. The first will bring:

1. the correct management of the entry and work on site of workers during the pandemic with consequent containment of the spread of the virus;

2. early detection of symptoms of infection, with a final reduction in treatment costs but above all in the risk of death caused by a late diagnosis of the disease;

3. the application of the containment measures provided for by the State-social partners agreement of 24 March 2020;

4. the automation of procedures without the involvement of human beings;

5. to the reduction of the costs necessary for compliance with the aforementioned protocol since CoFlex is configured as a very economical product;

6. to protect construction workers from Covid-19 and to improve working conditions in terms of safety but also to reduce mental and physical stress in the event of contagion.

In the long term, CoFlex can be implemented with other functions or be connected to other smart systems for the intelligent management of the construction site (Fig. 5). It can also be used in work sectors other than construction but also in other non-working contexts.

The device will be tested on a first construction site relating to the post-earthquake reconstruction of 2009 located in the Municipality of Fossa in the province of L'Aquila (Italy), together with other sensor systems for monitoring safety under construction. It could potentially affect about 8,000 workers distributed in 2,000 companies operating in post-earthquake reconstruction in L'Aquila. And in particular in the historic center of the city, where interference and potential gatherings of workers are a constant criticality. The CoFlex system would allow the company to monitor its staff, saving time and resources for supervisory personnel, as well as mitigating the risk itself.
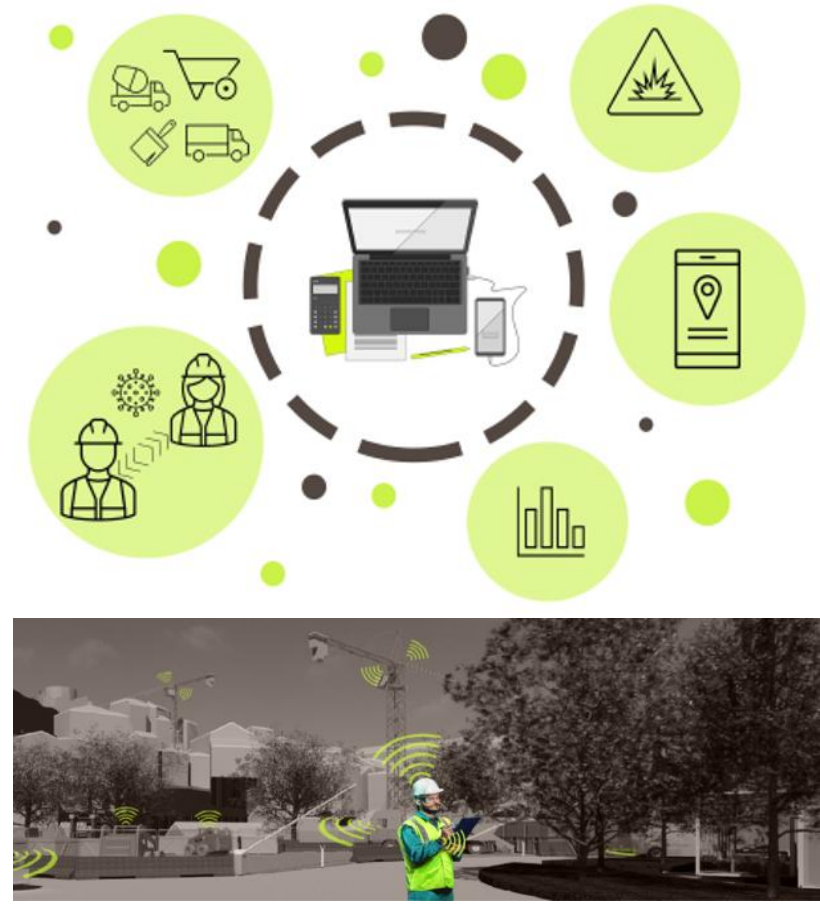

Figure 5: Example of connection of the CoFlex system with other sensor systems for site control and management

Situations similar to the historic center of L'Aquila are present in all the hamlets affected by the earthquake, where reconstruction is still partially stopped. For some of these urban areas, Construction Site Plans have been prepared [20, 21], a tool for coordinating the interventions provided to the safety coordinators and administrations for the management of the construction process and the programmed safety planning. These plans have often been developed considering the use of 4.0 technologies to implement the process management, control and safety system.

When CoFlex is released to the market, it will have multiple impacts. Primarily of a social nature. In fact, an injured worker does not only represent a direct cost for the company, but also a sort of failure for the company itself that was born to create economic and social well-being. Based on this concept and thanks to the constant search for innovation, an automatic electronic system has been developed with CoFlex to check the health and safety of the workers in general. The solution under development will help to increase the serenity and well-being of the worker who will feel protected in the workplace.

From an economic point of view, CoFlex will certainly contribute to creating well-being since, by reducing risks and related management costs, it will allow the resumption of activities and the companies that will employ it.

\section{CONCLUSIONS}

This article describes an innovative product designed to ensure the protection and safety of construction site workers. This is CoFlex, a flexible bracelet anti Covid-19 to protect construction workers.

The product will allow for each worker to monitor the interpersonal distance, body temperature, heart rate, oxygenation and in perspective the detection of PPE worn, the position on the construction site and falling. The system will issue early alerts to the worker and - always in respect of privacy - send the data to centralized software to take any necessary action to manage and mitigate the risk. 
CoFlex is based on a multidisciplinary methodological approach based on knowledge of construction site needs, with electronic, informatic and medical ones. Conceived for the construction industry, CoFlex's market opportunities can be extended beyond this sector by involving every economic and production area in which there is a risk of infection. Finally, it can be implemented with new functions as well as connected to other intelligent devices.

\section{ACKNOWLEDGEMENTS}

The article was written by M.R., E.L and P.V., while F.C. has revised. M.R. organized the paper and all contributions and made the revision. She is also the corresponding author.

All authors are involved in the CoFlex research project, of which P.D.B. is scientific manager. This research project was born to participate in Artes 4.02020 (Advanced Robotics and enabling digital Technologies \& Systems), of which Unirest S.r.l. was the proposing company in the figure of the Director Eng. Francesco Laurini, whom the authors thank.

\section{NOTE}

${ }^{1}$ We refer to the "Smart Safety Belt", the intelligent belt for safety on construction sites, conceived within the DICEAA research group, Univaq, "Construction production and rationalized management of the construction process on site" consisting of Pierluigi De Berardinis, Marianna Rotilio, Eleonora Laurini and Eng. Matteo Lucarelli.

\section{SOURCE OF ILLUSTRATIONS}

All images were made by M.R. and E.L., with the exception of Fig. 5, revised starting from the thesis "From BIM to Facility Management: towards building 4.0. Monitoring of the construction site of Palazzo Lazzaro in Fossa, L'Aquila" Supervisors: Prof. Pierluigi De Berardinis, Eng. Ph.D. Eleonora Laurini, Eng. Ph.D. Alessandra Tata, Tutor: Prof. Vincenzo Stornelli.

\section{FUNDING}

This research has not been funded.

\section{REFERENCES}

[1] Nwaogu J.M. and Chan A.P.C., 2021. Work-related stress, psychophysiological strain, and recovery among on-site construction personnel, Automation in Construction, 125, 103629, https://doi.org/10.1016/j.autcon.2021.103629.

[2] Liu, Y., Habibnezhad, M., Jebelli, H., Asadi, S. 2020. Ocular Artifacts Reduction in EEG Signals Acquired at Construction Sites by Applying a Dependent Component Analysis (DCA), In: Construction Research Congress 2020: Computer Applications - Selected Papers, Temple, Arizona, 8$10 \quad$ March, 1281-1289, https://doi.org/10.1061/9780784482865.135

[3] Jebelli, H., Byungjoo, C., SangHyun, L., 2019. Application of Wearable Biosensors to Construction Sites. I: Assessing Workers' Stress, Journal of Construction Engineering and Management, 145(12)

[4] Kim, Jung H., Jo, Byung W., Jo, Jun H., Lee, Yun S., Kim, Do K. 2021. Autonomous Detection System for Non-Hard-Hat Use at Construction Sites Using Sensor
Technology, Sustainability 13(3):1102, https://doi.org/10.3390/su13031102

[5] Sakhakarmi, S. and Park, J., 2020. Wearable Tactile System for Improved Hazard Perception in Construction Sites. Construction Research Congress 2020 American Society of Civil Engineers, http://dx.doi.org/10.1061/9780784482872.014

[6] Antwi-Afari, M.F., Li, H., Seo, J., Anwer, S., Yevu, S.K. and Wu, Z., 2020. Validity and reliability of a wearable insole pressure system for measuring gait parameters to identify safety hazards in construction, Engineering, Construction and Architectural Management, Vol. ahead-of-print No. ahead-ofprint, https://doi.org/10.1108/ECAM-05-2020-0330

[7] Kim, T.B., Ho, C.B. 2021. Validating the moderating role of age in multi-perspective acceptance model of wearable healthcare technology, Telematics and Informatics, 61, 101603, https://doi.org/10.1016/j.tele.2021.101603.

[8] https://www.ingegneri.cc/smart-safety-belt-la-cinturasmart.html/ (access 30.04.2021)

[9] Makram, B.H., Ali, F., Hala, N., Hadi, S. 2021. Analysis of COVID-19 Concerns Raised by the Construction Workforce and Development of Mitigation Practices, Frontiers in Built Environment, 7, 66, doi:10.3389/fbuil.2021.688495

[10] Alsharef, A., Banerjee, S., Uddin, S. M. J., Albert, A., and Jaselskis, E. (2021). Early Impacts of the COVID-19 Pandemic on the United States Construction Industry. Int. J. Environ. Res. Public Health 18, 1559, doi:10.3390/ijerph18041559

[11] Rotilio, M. 2020. Technology and resilience in the reconstruction process. A case study, Int. Arch. Photogramm. Remote Sens. Spatial Inf. Sci., XLIV-3/W1-2020, 117-123, https://doi.org/10.5194/isprs-archives-XLIV-3-W1-2020-1172020

[12] Laurini, E., Rotilio, M., Lucarelli, M., De Berardinis, P. 2019. Technology 4.0 for buildings management: from building site to the interactive building book, Int. Arch. Photogramm. Remote Sens. Spatial Inf. Sci., XLII-2/W11, 707-714, https://doi.org/10.5194/isprs-archives-XLII-2-W11-707-2019

[13] Jahmunah, V., Sudarshan, V.K., Oh, S.L., et al., 2021. Future IoT tools for COVID-19 contact tracing and prediction: A review of the state-of-the-science. Int J Imaging Syst Technol. 31: 455-471.

[14] Getz, W.M., Salter, R., Luisa Vissat, L. et al., 2021. A versatile web app for identifying the drivers of COVID-19 epidemics. J Transl Med, 19, 109.

[15] Ebekozien, A., Aigbavboa, C., 2021. COVID-19 recovery for the Nigerian construction sites: The role of the fourth industrial revolution technologies, Sustainable Cities and Society, 69, 102803, https://doi.org/10.1016/j.scs.2021.102803.

[16] Gulseren, D., Lyubykh, Z., \& Turner, N., 2021. Reimagining work safety behaviors in the light of COVID19. Industrial and Organizational Psychology, 14(1-2), 214216, doi:10.1017/iop.2021.45 
[17] Pamidimukkala, A., Kermanshachi, S., and Nipa, T. J., 2021. Impacts of COVID-19 on Health and Safety of Workforce in Construction Industry. In Proceedings of the 2020 ASCE International Conference on Transportation \& Development, https://doi.org/10.1061/9780784483541.039

[18] Integrazione al protocollo del 14 marzo 2020 "Protocollo condiviso di regolamentazione per il contenimento della diffusione del Covid-19 nei cantieri”, Gazzetta Ufficiale (2020).

[19] Ciribini A.L.C., 17/05/2018. Dalla Fabbrica 4.0 al Cantiere 4.0: Nuovi Modelli di Business per le Imprese di Costruzioni, Ingenio web, 17th May 2018.

[20] De Berardinis, P., Di Giovanni,G., Laurini, E. Rotilio, M., 2018. Progettare l'organizzazione del cantiere di recupero nell'ambito della ricostruzione post sismica all'Aquila. In: 6th Convegno Internazionale ReUSO, Messina, 1489-1500.

[21] Lucarelli, M., Laurini, E., Rotilio, M., De Berardinis. P., Metodo BIM: gestione dei cantieri edilizi nei centri colpiti da calamità naturali. In: 6th Convegno Internazionale ReUSO, Messina, 2531-2542. 